peutic principles as may be suggested by a general study of pathology.

One explanation I may perhaps be allowed to offer. Nothing can be further from my wish than to sanction in any way the detention of insane persons at home. Whenever insanity has manifested itself to such an extent as to justify the requisite certificates, the patient sbould at once be removed to an asylum. No private house can possibly command the varied resources and facilities for treatment possessed by a large and well-contucted institution arranged exclusively for persons so afflicted. And not being myself connected with any asylum, this opinion may perhaps be received as given in sincerity. But, practically, we find that a certain time does al ways exist between the first manifestation of the symptoms of insanity and the determination to remove the patient to an asylum, and it is to this interval only that my remarks are intended to apply.

The family medical attendant will act wisely, as a general rule, in mentioning to the friends the possible necessity of legal restraint from the commencement of the attack; but there are always feelings-prejudices, if we may venture to call them so-which militate strongly against the employment of the legal forms required for admission to an hospital for the insane, and which press for "a trial at home." Then the medical attendant is sometimes painfully situated, and the absurd harshness of the law as regards his responsibilities must, and at present does, tend to prevent the early removal of the patient. The law very properly requires clear proof of the fact of insanity, but the expression of a scientific or technical opinion should be plainly distinguished from the quasi-magisterial act which consigns the inhabitant of a free country to a place of detention, and these totally distinct functions, with their attendant responsibilities, be assigned to different persons.

The forms of insanity which we are generally called upon to treat at the patient's ordinary residence are, acute mania, melancholia, and puerperal insanity, and the remarks which I purpose making on the medical treatment will be restricted to these. I shall, however, just notice the various conditions in volved in the general management of the patient under such circumstances.

Welbeck-street, Cavendish-square, Dec. 1863.

\section{TINCTURE OF SESQUICHLORIDE OF IRON IN DELIRIUM TREMENS.}

BX JAMES GREY GLOVER, M.D. EDIN.,

'LATE HON. SURGEON TO THE SOTTH SHIELDS AND WISTOH DISPENSARY, ETC.

I saw R_- a drayman, for the first time on Sunday morn. ing, October 11th, at half-past nine. He had been under the treatment of another practitioner for five days; probably the ordinary treatment by purgatives, opiates, and support. The disease was still at its height. There had been no sleep for five days. He was so unruly as to require two men in the room with him, and so threatening towards his wife that she had to keep out of the room. Sweat stood in drops on the skin, \&c. A good sign about him was the avidity with which he disposed of a mutton chop during my visit. I gave him one grain of opium every three hours, and, in the interval of the opiates, fifteen drops of the tincture of the sesquichloride of iron; also broth, and half an ounce of spirit every three hours.

Sunday evening.- He seemed quieter, but had no sleep, and could not be prevailed on by his attendants to keep in bed. I gave him forty drops of tincture of opium, to be repeated in six honrs if still sleepless; to continue the iron and the support. He became so unruly in the night that two policemen were ealled in to the aid of four men. The policemen removed him to the police-station, but soon released him at my request. As in most such cases, the control over him was more a matter of tact than of force. Though his attendants found the greatest difficulty in managing him, I could get him to do anything I pleased.

Monday morning. -I found him much quieter and alone in the house with bis wife. The muscles were much steadier. At balf-past one P. Mr. he complined of feeling tired, lay down in bed and went to sleep till thirty-five minutes past three, then had some food and went to sleep again at five o'clock for three hours and a half, and so on during the night.

Tuesday. - Though somewhat stupid-as a man should be who has only had a night's sleep in a week-he was quite rational and manageable. From this time he rapidly and satis factorily recovered.

Remarks. - The therapeutics of delirium tremens are in such a state of confusion and confliction that I make no apology for submitting a new suggestion to the profession though, supported at present by only a single case. He must be a man of rare decision who is at once clear as to his duty in the treatment of delirium tremens : whether to give a dose of digitalis, which a few years ago would have been thought simply an overpower. ing poison, and which given in delirium tremens seems occasionally to act as such; whether to give antimony and purgatives, or beef-tea and support ; whether to pour in spirit or to withhold and eliminate it. There is no more discraditable chapter in all the practice of physic than the treasment of delirium tremens. Little importance can be attached to one case, but it is sufficient to justify further experiment. In twenty-seven hours the tremor was almost gone, the patient became quiet and manageable, and a natural sense of fatigue ushered in actual sleep, which speedily restored the patient to health. At any rate, tincture of iron seems a more natural and safe remedy for a pale, weak, sweating, timid, and tremulous drunkard than tincture of digitalis; and my object will be attained if the profession give it a fair and full trial. Probably larger doses than I gave would be well borne.

Highbury-park West, 1863.

\section{ARE THE ROSE SPOTS OF TYPHOID FEVER} ALWAYS DIAGNOSTIC OF THAT AFFECTION?

\section{BY HFNRY KENNEDY, M.D.}

THE three following cases appear to me so important, as bearing on the question stated above, and thus opening up a new phase of this subject, that I venture to submit them to the notice of the profession :-

CASE 1.-Mr. C-_ aged twenty.three years, admitted into pay ward of Sir Patrick Dun's Hospital on the evening of the 15th of November last. In my absence he was then seen by my colleague, Dr. Moore. The next day I had also the assistance of Dr. Burke, one of the physicians of Steevens' Hospital, who had been attending the patient previously with Mr. White, of Henry-street. I was informed that the patient had but just recovered from a severe attack of scarlatina, when he was seized with all the symptoms of enteric fever, attended by sharp purging, and followed in a few days by a well-marked crop of rose-coloured spots, which were confined to the chest and abdomen. The statement was made without any inquiry on my part; and Dr. Burke further remarked that as the spots dis. appeared, the pain, which had been localized, seemed to become general, and so acute that he had been induced to treat the case for peritonitis, by leeching, \&c. It is enough to add that matters went from bad to worse, and that the patient died on the fifth day from his admission into the hospital, having had great tympanitis, with pain drffused over the entire abdomen, and constant vomiting of a dark-green fluid, which was in much greater quantity than was swallowed. The diarrhcea, however, had entirely ceased. He died about the twelfth day from the onset of the fever. On examiuation after death, the results of acute peritonitis were found, with rather more than a pint of liquid effusion. There was no perforation, and all the lower part of the ileum, which was carefully examined, presented the normal appearance.

CAS 2.-Mr. - aged twenty-seven, admitted into pay ward Nov. 12 th. He had been under my care from the beginning of his illness, which commenced with the ordinary symp. toms of fever. His tongue shortly became red and furred; eyes injected; sleep quite broken, and with a tendency to vomiting. The depression, too, was very great, and he complained much of severe pains through his limbs. I had been watching closely for any appearance of spots, and on the fourth day from admission, being now eleven days ill, I found three distinct rose. coloured ones on the sides of the chest. The day after they had increased to eleven, some of these being on the abilomen. At this period I brought my colleague, Dr. Moore, to see them, and he confirmed what has been stated. It is enough to add of this case, that there was no other symptom of typhoid fever, neither diarrhœa, tympany, nor pain on pressure. His recovery was delayed, however, by a slight attack of diphtheria, which I have also met in other cases of fever. The spots had disap. peared by the fifth day from their first appearance.

CASE 3.-Mrs. -, a young married woman, admitted into 